A Publication of the Systems \& Psychosocial Advances Research Center (formerly the Center for Mental Health Services Research) A Massachusetts Department of Mental Health Research Center of Excellence

Volume 8

Issue 4

2011

\title{
The Impact of Suicide Calls on Police
}

\author{
Barry N. Feldman, Ph.D., Albert J. Grudzinskas, Jr., J.D., Bernice Gershenson, MPH,
} Jonathan C. Clayfield, MA, LMHC, Richard P. Cody, J.D.

$\mathrm{D}$ ata collected in 2007 by the Centers for Disease Control and Prevention revealed that suicide occurred at rates nearly twice that of homicide. For all age groups combined, suicide ranked as the eleventh leading cause of death in the US and among the top five causes in several age groups in 2007 (CDC, 2011), (table 1). Police officers are the first responders to crises, yet little is known about the impact and stressors of responding to completed suicide calls.

\begin{tabular}{|cc|}
\hline Table 1. Suicide Rank as Cause of Death \\
\hline Age Group & Suicide Rank \\
\hline $\mathbf{1 0}-\mathbf{1 4}$ & $4^{\text {th }}$ \\
$\mathbf{1 5}-\mathbf{2 4}$ & $3^{\text {rd }}$ \\
$\mathbf{2 5}-\mathbf{3 4}$ & $2^{\text {nd }}$ \\
$\mathbf{3 5}-\mathbf{4 4}$ & $4^{\text {th }}$ \\
$\mathbf{4 5}-\mathbf{5 4}$ & $5^{\text {th }}$ \\
Centers for Disease Control $[C D C], 2011$ \\
\hline
\end{tabular}

\section{Police Stressor Survey}

In a preliminary study of over 225 officers in Massachusetts, we identified issues and circumstances reported by officers dealing with suicides. We asked police officers to identify the issues or specific circumstances related to responding to suicide calls that could cause/have caused them to feel the most stress or anxiety.

A total of 225 usable surveys were obtained, with 684 issues/circumstances identified. Findings suggest that suicide calls present personal and professional challenges, with short and long-term impact for police officers, their departments, and their

\begin{tabular}{|lc|}
\hline \multicolumn{2}{|c|}{ Table 2. } \\
\hline \multicolumn{1}{|c|}{ Stressor } & $\begin{array}{c}\text { \% Reporting } \\
\text { Stressor }\end{array}$ \\
Dealing with survivors & 39 \\
\hline Emotional impact on officer & 35 \\
Young victim & 30 \\
\hline Managing crime scene & 29 \\
Emotional impact on survivors & 26 \\
Victim known to officer & 19 \\
\hline Suicide method & 16 \\
\hline Reason for suicide & 15 \\
Graphic/gruesome death & 13 \\
\hline Officer safety & 13 \\
\hline Death notification & 12 \\
\hline
\end{tabular}

communities. These data show that suicide calls are often critical incidents in police officers' careers and are among the highest anxiety- and stress-provoking circumstances to which police officers must respond (table 2).

\section{"Normal" Work Stressors}

Policing is a high-demand and high-stress profession (Miller, 2008), in which police officers are exposed to a wide variety of stressors. "Normal" work stressors typically fall into two categories: (1) stressors on-thestreet (e.g., dealing with extremes such as weather and high risk situations, shift changes, experiencing "high impact" crime areas, and fear of serious injury or death); and (2) departmental stressors (e.g., lost promotional opportunities, mistrust of management, punitive discipline, and police brutality issues). 


\section{Critical Incident Stressors}

In addition to these routine ongoing stressors, officers often experience critical incident stress. A critical incident $(\mathrm{CI})$ is any event that has an unusually powerful, negative impact on police personnel because the event exceeds the range of ordinary work-related stressors or hassles (Everly \& Mitchell, 1997; Miller, 2008). In one report, $26 \%$ of officers involved in CIs experienced some form of Post-Traumatic Stress Disorder (PTSD) one month later (Martin, McKean \& Veltkamp, 1986; Koch, 2010; Pienaar, Rothman \& Van De Vijver, 2006). This was seen to be especially true after a call involving a death. Significant literature exists to support the idea that police officers experience high-level stress when arriving on-scene at a traumatic incident (Brown \& Campbell, 1994; Kirschman, 1997; Paton \& Violanti, 1996).

\section{Impact of Critical Incidents}

Failure to acknowledge and address the emotional impact of CIs may result in serious, and sometimes devastating, personal and professional consequences for those officers involved, both on individual and departmental levels. Research on predictors of police suicide (Violanti, 2004, Cross \& Ashley, 2004) has demonstrated that CI exposure and PTSD symptoms seem to significantly increase:

$\begin{array}{ll}\text { - } & \text { Alcohol Use } \\ \text { - } & \text { Suicidal Ideation/Suicide } \\ \text { - } & \text { Dood Disturbance } \\ \text { Use of Excessive Force }\end{array}$

Suicide of a police officer represents a major CI. The $\mathrm{CDC}$ reports a suicide rate for the general population of nearly 12 per 100,000 (Heron et al., 2009). Police suicide rates are estimated to be significantly higher at 18 per 100,000 (Ritter, 2007). Studies have documented that within a specific period, some law enforcement agencies have had more officer deaths from suicide than from line-of-duty homicides (Hackett \& Violanti, 2003).

\section{Barriers}

Despite the tragedy of suicide and its toll among police officers, a major barrier for dealing with this issue is the pervasive code of silence consistent within the law enforcement culture. Stigma surrounding mental health problems prevents officers from self-reporting depression or other problems, fearing that they will be perceived as being weak. Reluctance to self-disclose emotional problems stems from fears of reassignment and loss of weapon-carrying privileges. Co-workers are often hesitant to turn in a troubled officer despite concerns about a comrade's need for help (Miller, 2008). Even with the high rate of police suicide, "experts estimate that less than 10 percent of the 18,000 police departments nationwide actively work to prevent suicides within their ranks" (Antlfinger, 2008).

\section{Recommendations for Police Training and Mental Health Providers}

The Special Commission on Massachusetts Police Training (2010) found that Massachusetts spends only $\$ 187$ annually per officer for training in general. By comparison, New Hampshire spends $\$ 933$, and Vermont spends $\$ 1,525$. The expertise to provide such training and to help officers manage CI stress currently exists. Despite this, it is implemented in only a few departments. Based on feedback we have received, we recommend that officers receive mandatory training to:

- Detect suicidal risk in officers and the public

- $\quad$ Facilitate appropriate referrals for help

- Develop/enhance skills to communicate with surviving family/friends

- Understand challenges inherent in suicide calls

- $\quad$ Recognize signs and symptoms related to

CI stress associated with responding to suicide calls

Delivering mental health care to the law enforcement community is challenging. Police officers often resist counseling for reasons including officers being skeptical of outsiders and having difficulty trusting mental health professionals. Conversely, therapists sometimes do not understand police work, nor can they comprehend the daily stresses officers encounter (Kureczka, 1996).

We recommend that counselors have a thorough understanding of policing, as well as comprehensive knowledge of the police force and its demographics. Therapists must be familiar with the organization of the police department and its power structure to understand the work environment of affected officers. Further, building rapport and assuring officers of the confidentiality of information revealed is essential and requires time and diligence by mental health professionals. Through such efforts, the therapeutic effects of counseling can be realized.

An electronic copy of this issue brief with full references can be found at http://escholarship.umassmed.edu/pib/vol8/iss4/1 


\section{References}

Antlfinger, C. Few police agencies address suicides within ranks. Associated Press, July 22, 2008. Last accessed September 29, 2009 at: http://www.sfgate.com/cgi-bin/article.cgi?f=/n/a/2008/07/22/national/a104836D42.DTL\&hw=gun\&sn=019\&sc=178\#ixzz0SVUMgoOz

Brown, J. \& Campbell, E. (1994) Stress and policing: Sources and strategies. New York: John Wiley \& Sons.

Centers for Disease Control and Prevention. Leading Causes of Death Reports. Atlanta, GA: National Center for Injury Prevention and Control. Last accessed May 13, 2011 at http://www.cdc.gov/injury/Images/LC-Charts/10lc\%20-\%20By\%20Age\%20Group\%2020067_6_09-a.pdf

Centers for Disease Control and Prevention (CDC). Web-based Injury Statistics Query and Reporting System (WISQARS) [Online]. (2010). National Center for Injury Prevention and Control, CDC (producer). Last accessed May 10, 2011. Available from URL: www.cdc. gov/injury/wisqars/index.html.

Cross, C.L. \& Ashley, L. (2004). Police trauma and addiction: coping with the dangers of the job. FBI Law Enforcement Bulletin, October, pp. 24-32.

Everly, G. \& Mitchell, J. (1997). Critical incident stress management (CISM): A new era and standard of care in crisis intervention. Ellicott City, MD: Chevron.

Hackett, D.P. \& Violanti, J.M. (2003). Police Suicide: Tactics for Prevention. Springfield, IL. Charles C. Thomas Publishers. .

Heron MP, Hoyert DL, Murphy SL, Xu JQ, Kochanek KD, Tejada-Vera B. Deaths: Final data for 2006. National vital statistics reports, (57), 14. Hyattsville, MD: National Center for Health Statistics. 2009.

Kirschman, E. (1997) I love a cop: What police families need to know. New York: Guilford Press.

Koch, B. (2010) The Psychological Impact on Police Officers of Being First Responders to Completed Suicides. J Police Crim Psych 25: 90-98.

Kureczka, W. (1996). Critical incident stress in law enforcement. FBI Law Enforcement Bulletin, 65 (:2/3): 10-16.

Martin, C. A., McKean, H. E., \& Veltkamp, L. J. (1986). Post-Traumatic Stress Disorder in Police Working with Victims: A Pilot Study. Journal of Police Science and Administration, 14, 98-101.

Miller, L. (2008). Military psychology and police psychology: Mutual contributions to crisis intervention and stress management. International Journal of Emergency Medicine,10 (1): 9-26.

Paton, D. \& Violanti, J. (Eds.) (1996) Traumatic stress in critical occupations: Recognition, consequences, and treatment. Springfield, IL: Charles C. Thomas.

Pienaar, J., \& Rothmann, S. (2006). Job Stress in the South African Police Service. South African Journal of Industrial Psychology, 32(3), 72-78.

Ritter, J. (2007). Suicide rates jolt police culture. USA Today. February 7, 2007. Retrieved on September 28, 2009 at: http://www.usatoday. com/news/nation/2007-02-08-police-suicides_x.htm.

The Special Commission on Massachusetts Police Training: Results and Recommendations. July, 2010 Sen. James E. Timilty \& Rep. Michael A. Costello, Co-Chairs. Retrieved on: November 5, 2010 at: http://www.mass.gov/Eeops/docs/mptc/statewide_police_training report_final.pdf.

Violanti, J. (2004). Predictors of police suicide. Suicide and Life-Threatening Behavior, 234 (3), 277-283.

Impact of Suicide Calls on Police - Barry N. Feldman, Ph.D., Albert J. Grudzinskas, Jr., J.D., Bernice Gershenson, MPH, Jonathan C. Clayfield, MA, LMHC, Richard P. Cody, J.D. 